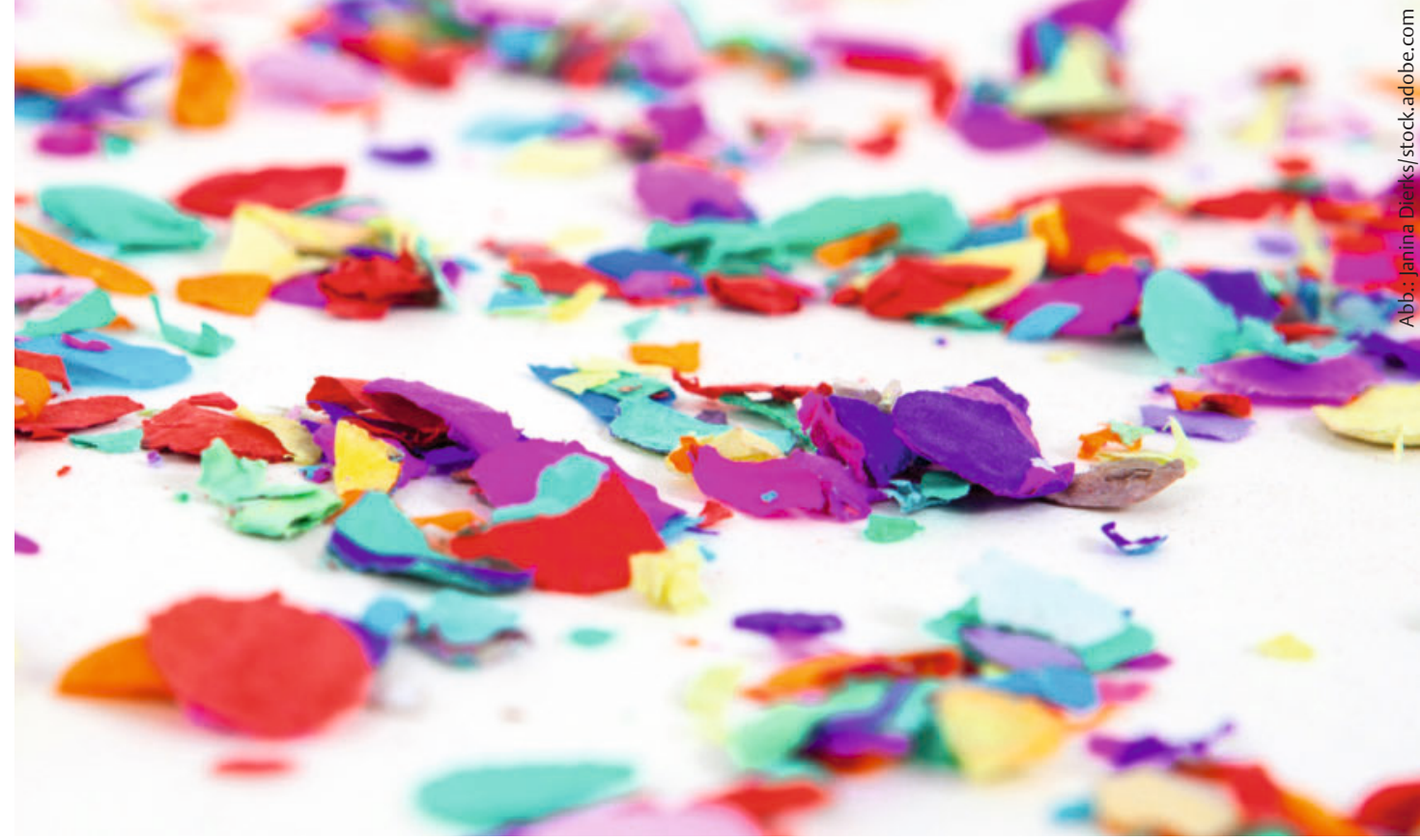

Editorial

ABB. Janina Dierks/stock.adobe.com

\title{
Viel Glück statt guter Vorsätze
}

Nie mehr gute Vorsätze fürs neue Jahr! Das habe ich mir dieses Mal fest vorgenommen. Dabei sah es im letzten Jahr noch richtig gut aus. Zunächst die üblichen Vorsätze mit mehr Sport, weniger Stress und das ein oder andere Kilo abnehmen. Dann noch mit vielen anderen Kollegen bei der TheraPro in Stuttgart voller Schwung ins neue Jahr mit der Aussicht auf viele entscheidende Veränderungen.

Und dann kam Corona ...! Statt Sport stiegen mein Fernsehkonsum und das Stresslevel samt Körpergewicht. Auch von den verheißungsvollen Veränderungen in der Physiotherapie blieb nicht viel übrig: Die Reform der Ausbildung (○ PHYSIOPRAXIS 9/20, S. 8) und Schritte Richtung Akademisierung (๑ PHYSIOPRAXIS 7-8/20, S. 7) sind in weite Ferne gerückt, die Blankoverordnung (o PHYSIOPRAXIS 5/20, S. 7) ist nach wie vor nicht mehr als eine Idee und in Sachen Vergütungssteigerung kann man sich wohl über jedes „Prozentchen“ mehr freuen (॰ PHYSIOPRAXIS 7-8/20, S. 6).

\author{
„Gesetzliche \\ Neuregelungen \\ lassen auf sich \\ warten.“
}

Ich empfehle daher einen Strategiewechsel für 2021. Zunächst die Befreiung an Altlasten: Die Argentinier pflegen an Silvester Papierschnipsel aus geschredderten Unterlagen „schneien“ zu lassen, um sich von Altlasten zu lösen. Um uns also von dem Frust mit Krankenkassen und der Gesundheitspolitik zu befreien, könnten wir abgesetzte Rezepte, Widersprüche bei den Kassen und vergebliche Stellungnahmen auf die Straßen „schneien“ lassen. Und: Statt auf gute Worte aus Berlin könnten wir mehr aufs Glück vertrauen. Wie in Griechenland das zu Silvester gebackene Basiliusbrot mit versteckter Münze, könnten wir „Spahn“-Brötchen backen. Wer die Münze im Brötchen erwischt, dem steht eine besonders glückliche Vergütungssteigerung bevor.

Ab und an verlieren wir einfach den Mut. Doch etwas Humor ist durchaus erlaubt. Dennoch heißt es dranzubleiben und voller Tatendrang ins neue Jahr zu starten. Viel Glück dafür!

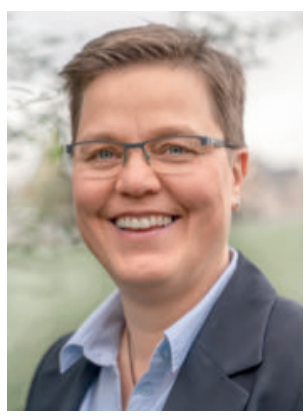

Dr. Claudia Kemper Physiotherapeutin und Themenscout

Herzlichst Ihre 